\title{
From the President OF IALLT
}

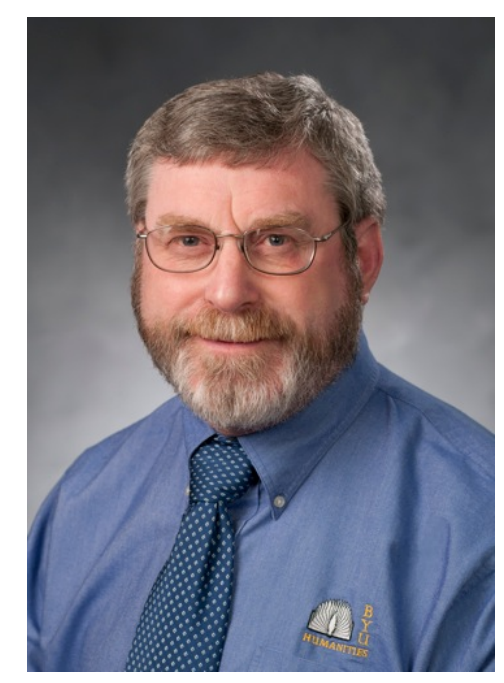

Harold Hendricks

Brigham Young University

As we come to the end of another year, it is my pleasant task to review the activities of our organization since the Spring issue of the Journal appeared. Many of us spent an enjoyable few days together at the IALLT 2013 Conference in Ft. Lauderdale, Florida where we were wonderfully hosted by Frank KrugerRobbins of Pinecrest School, Michael Horswell of Florida Atlantic University, and their teams of excellent staff and students. The facilities of both institutions were amazing and the Florida weather combined to match the theme of Sunshine and Cloud Apps as we met together in both conference sessions and social activities. Along with the interesting workshops and sessions, we were treated to a stirring and enthusiastic plenary speech by Yo Azama, the 2012 ACTFL 
Teacher of the Year. It was surely a memorable conference and we thank all those whose hard work made it possible.

Each IALLT conference marks the transition of officers, and as we who are newly appointed try to fill the shoes of those who preceded us, we have a profound respect for the time and effort that was expended by our colleagues as they filled their roles on the executive board and within the council. We especially thank our Past-President, Ute Lahaie, for her excellent leadership and clear vision over the past two years. Our gratitude extends to all who served the IALLT family in positions of leadership, as affiliate representatives, writers and editors, and in all the various committees. Our organization is made up completely of volunteers who already carry heavy burdens within their own institutions and families. Their commitment to IALLT is born of a love of service and a passion for the work IALLT strives to carry out.

Since September we have also learned much from four of our colleagues who presented IALLT webinars on several interesting topics. Those webinars were recorded and are archived at our website, www.IALLT.org, as a member benefit, so if you are wondering about joining IALLT, here is a good reason. Another slate of excellent webinar presentations is planned for the upcoming year, thanks to our excellent webinar team.

Our Managing Editor, Dan Soneson, has provided us with another interesting issue with papers that address elements of lab planning, trends in current practice, and research on ratings and writing. We have wisdom from veteran IALLT members Jack Burston and Judy Shoaf and research from Professor Jie Zhang and graduate students Betsy Lavolette and Kelsey White that will help us move forward in our ever-changing efforts to improve language learning and teaching.

It is an exciting time to be involved with language and technology. There are so many interesting and novel ideas, applications, and devices that appear every day that can excite both teacher and learner to better communicate with other languages and cultures. I am humbled to be called upon to lead such a wondrous group of people dedicated to making a diverse world more connected. Please let us know what you are doing. Publish in the Journal, present to us in a webinar, connect with your regional groups, and share the journey with us.

Harold Hendricks

President of the International Association for Language Learning Technology 